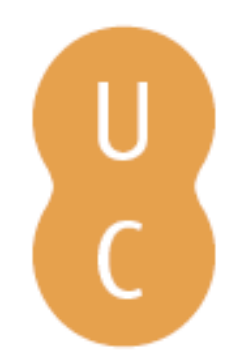

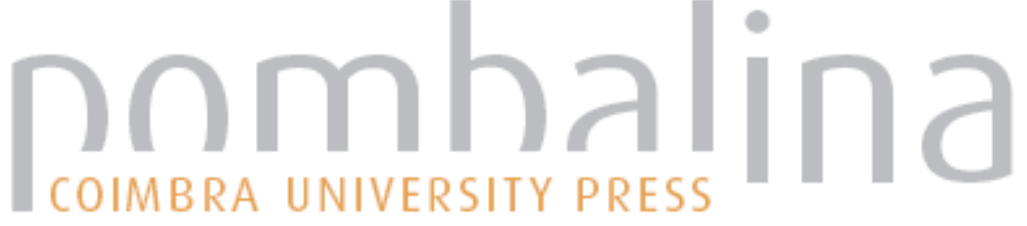

\section{El método transcendental: su desarrollo en el Fichte de Jena}

Autor(es): $\quad$ Rivera de Rosales, Jacinto

Publicado por: Imprensa da Universidade de Coimbra

URL

persistente:

URI:http://hdl.handle.net/10316.2/32227

DOI:

DOI:http://dx.doi.org/10.14195/978-989-26-0361-2_3

Accessed : $\quad$ 26-Apr-2023 12:05:37

A navegação consulta e descarregamento dos títulos inseridos nas Bibliotecas Digitais UC Digitalis, UC Pombalina e UC Impactum, pressupõem a aceitação plena e sem reservas dos Termos e Condições de Uso destas Bibliotecas Digitais, disponíveis em https://digitalis.uc.pt/pt-pt/termos.

Conforme exposto nos referidos Termos e Condições de Uso, o descarregamento de títulos de acesso restrito requer uma licença válida de autorização devendo o utilizador aceder ao(s) documento(s) a partir de um endereço de IP da instituição detentora da supramencionada licença.

Ao utilizador é apenas permitido o descarregamento para uso pessoal, pelo que o emprego do(s) título(s) descarregado(s) para outro fim, designadamente comercial, carece de autorização do respetivo autor ou editor da obra.

Na medida em que todas as obras da UC Digitalis se encontram protegidas pelo Código do Direito de Autor e Direitos Conexos e demais legislação aplicável, toda a cópia, parcial ou total, deste documento, nos casos em que é legalmente admitida, deverá conter ou fazer-se acompanhar por este aviso. 
Diogo Ferrer

Coordenação

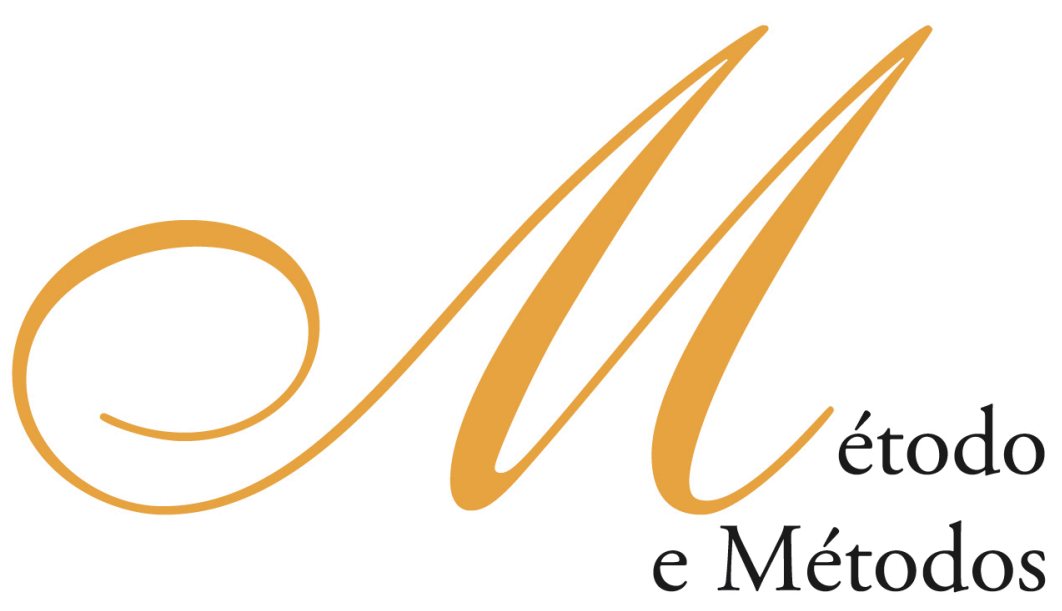

do Pensamento Filosófico 


\section{COORDENAÇÃO EDITORIAL \\ Imprensa da Universidade de Coimbra}

URL: http//www.imp.uc.pt

\section{CONCEPÇÃO GRÁFICA}

António Barros

PRÉ-IMPRESSÃO

Victor Hugo Fernandes

EXECUÇÃO GRÁFICA

Inova - Artes gráficas

ISBN

989-8074-02-7

DEPÓSITO LEGAL

$257236 / 07$

(C) Março 2007, Imprensa da Universidade de Coimbra

OBRA PUBLICADA COM O APOIO DE:

Centro de Estudos Clássicos e Humanísticos

FCT Fundação para a Ciência e a Tecnologia MINISTÉRIO DA CIÊNCIA E DA TECNOLOGIA 
Diogo Ferrer

Coordenação

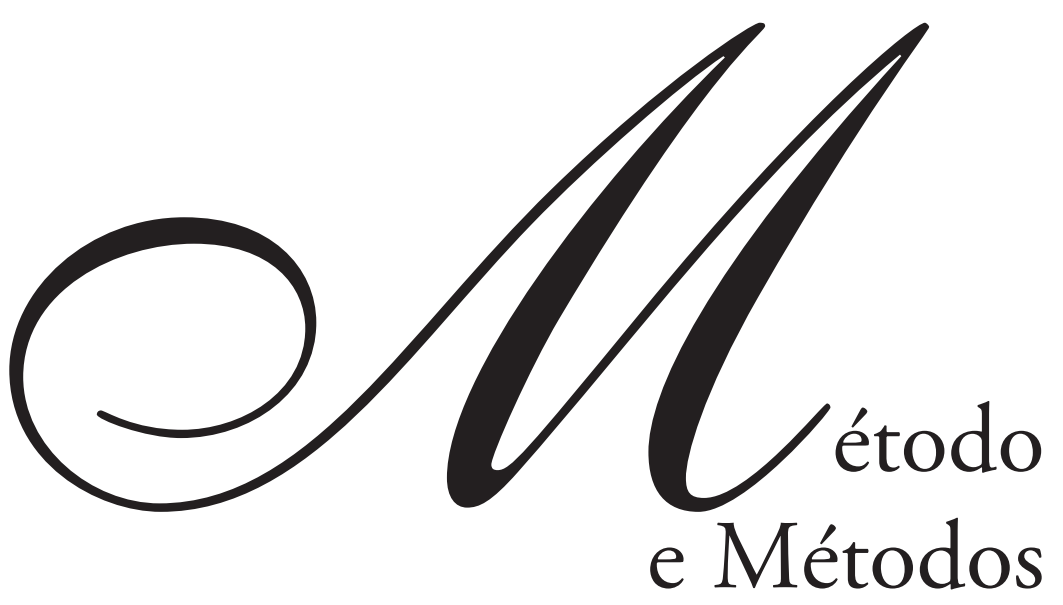

do Pensamento Filosófico

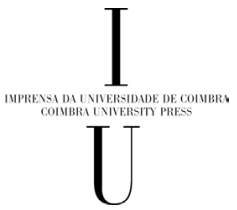

- COIMBRA 2007 

Jacinto Rivera de Rosales

UNED, Madrid

El método transcendental. Su desarrollo en el Fichte de Jena

\section{Resumen}

Organizaré mi exposición alrededor de tres puntos básicos que delimitan el tema, pues marcan territorios diferentes, modo y ámbitos distintos en el pensar filosófico.

1. ${ }^{\circ}$ La estructura del "para sí o "für sich" como carácter propio de la subjetividad, que todos estos idealistas alemanes (Kant, Fichte, Schelling y Hegel) comparten y que funciona en ellos como núcleo de su primer principio y de su método.

2. ${ }^{\circ}$ La finitud, que distingue el método transcendental de Kant y Fichte en Jena del modo de pensar, ya no transcendental sino, podríamos decir, especulativo, de Schelling y Hegel, y en el que habría que incluir también al Fichte de Berlín.

3. ${ }^{\circ}$ El modo genético de deducción, que es común a Fichte, Schelling y Hegel, y gracias al cual los englobamos en la denominación de Idealismo alemán y los distinguimos de Kant, o de la fenomenología de corte idealista.

En la zona de intersección que comparten esos tres círculos se sitúa la singularidad de la posición fichteana en su período jenense. 


\section{El "para sí» como estructura básica de la subjetividad}

Podríamos definir el método transcendental como aquél que indaga la realidad, el alcance y la estructura de la experiencia o de las experiencias (la objetiva, la moral, la estética), es decir, la realidad que lo es para el sujeto, la única de la que él puede hablar, y en concreto trata de explicar esas experiencias desde sus condiciones de posibilidad o fundamentos. Dichas condiciones de posibilidad no las busca en un objeto de experiencia, en un objeto inmanente a ella, como lo hacen las ciencias, sino en estructuras que la articulan en su conjunto y le dan sentido; por ese horizonte de totalidad en el que se sitúa la indagación filosófica, esas estructuras están situadas en otro nivel o modo de ser que Kant denomina «transcendental». Por tanto, esas estructuras son comprendidas como acciones de una subjetividad transcendental, la cual tiene un modo de ser no mundano o cósico; no es el sujeto empírico, que, al ser un objeto inmanente a la experiencia, ha de ser explicado y comprendido desde ella como los otros objetos, sino una subjetividad que es acción o ser originarios, espontaneidad. En efecto, en la reflexión transcendental no interesa la descripción meramente fenoménica de lo que ocurre, sino que se analizan los criterios que validan universal y necesariamente esos diversos tipos de experiencia, que marcan los límites de su modo de ser. Esto lo hace así a fin de poner orden en el mundo de las experiencias y en las exigencias de la razón; si de ese modo se consigue la armonía, el experimento estaría logrado(1). Por eso la $K r V$ se presenta como un "tratado del método" (2).

Pues bien, el momento originario o modo de ser específico de la subjetividad en cuanto tal, empezando por su nivel transcendental, es precisamente su estructura de "para sí», su saber de sí, su autorreferencia o transparencia a sí como acción ideal y real. El primer Fichte hablaba en

\footnotetext{
(1) Kant, $K r V$ B XX-XXI.

(2) Kant, $K r V$ B XXII; A 83, B 108-109.
} 
este sentido de la Tathandlung, porque "para sí» indica acción, y no podría darse en algo cósico, fijo, parado(3): «La esencia del Yo es actividad»(4), una actividad libre que es sabiendo de sí. Esa unión de saber y realidad es lo que Fichte denomina «intuición intelectual». Gracias a esa autoconciencia originaria el Yo se constituye como tal atribuyéndose a sí la acción y el pensar ${ }^{(5)}$. «El Yo incluye, en la intuición y en el concepto de sí mismo, todo lo que es originario (pero nada es originario sino lo libre)»(6).

Podríamos decir que es en estas filosofías, las de Kant y el Idealismo alemán, donde se comprende en verdad el modo de ser propio de la subjetividad, que no es cosa opaca, ni tampoco res cogitans, porque no es res, sino acción real-ideal que sabe de sí. Eso es lo que la capacita para servir de principio filosófico, y por lo que sólo admite ser colocada ahí, en el principio (aunque no necesariamente en el comienzo del discurso)(7). La libertad o subjetividad libre, al ser autonomía o incluso autoposición, es compatible con el sistema únicamente si ocupa su primer principio y no es entendida como algo deducido y heterónomo, sino colocada en el lugar de donde parte el sentido. Por eso no cabe poner el fundamento explicativo de los diversos tipos de experiencia en una realidad transcendente al sujeto, ya se la piense como objeto, como estructura o como Dios. En cualquiera de esas opciones se desemboca en lo que Fichte denomina «materialismo transcendental» $(8)$, pues convierte a la libertad en algo derivado y destruye

(3) El Yo «es a la vez lo que actúa y el producto de la acción, lo activo y lo producido por la actividad; acción (Handlung) y hecho (That) son una y la misma cosa; y por eso el Yo soy es expresión de una Thathandlung, y además la única posible» (Fichte, Grundlage, FW I, $96=G A \mathrm{I} / 2,259)$.

(4) Fichte, WLnm (= Doctrina de la ciencia, nova methodo), GA IV/3, 375; véase también p. 336.

(5) Véase sobre este asunto el Versuch ( $F W$ I, 521-530 = GA I/4, 271-278); Zweite Einleitung, §§ 5-6 (FW I, 463ss. = GA I/4, 216ss); Vergleichung des vom Herrn Prof. Schmid aufgestellten Systems mit der $W L(F W$ t. II, pp. 442ss = GA t. I/3, pp. 254ss. $)$.

(6) Fichte, Sittenlebre de 1798 ( FW IV, $38=$ GA I/5, 52).

(7) En el sentido propio de Prinzip y no necesariamente de Anfang.

(8) Fichte, Vorlesungen über die Bestimmung des Gelehrten ( $F W$ VI, 294-295 = GA I/3, 28). Véase también Fichte, Erste Einleitung, FW I, 437-8 = GA I/4,197-198; Sittenlehre de 1798, § 10, $F W \mathrm{IV}, 133=G A \mathrm{I} / 5,127$. 
la autonomía del yo, su modo de ser originario. Toda explicación del Yo desde otra cosa le destruye, anula su "para sí» y lo convierte en cosa para otro o desde otro ${ }^{(9)}$. Ese ser desde sí lo conceptúa Fichte como autoposición (Selbstsetzung).

Por esa estructura del para sí, la subjetividad sólo puede ser desde sí, pues únicamente lo que elabora por sí misma(10) es real para ella; sólo conocemos lo que elaboramos desde nosotros mismos ${ }^{(11)}$. En caso contrario no se enteraría y no podría hablar de esa otra realidad, ni menos hacer filosofía de ella. Ése es el fundamento de todo lo a priori, que son las estructuras mediante las cuales la subjetividad elabora "para sí» la realidad, desde el espacio y el tiempo como formas primarias de aceptación y elaboración del mundo, hasta las ideas de la razón y el imperativo categórico con las que comprende su propia acción, pasando por los esquemas, las categorías y los principios. Eso ocurre en Fichte también con el sentimiento, las sensaciones, el cuerpo propio, etc. Por su estructura de "para sín, la subjetividad es espontaneidad responsable de sí, tanto en su conocer como en su acción real-ideal, lo que llamamos libertad, de modo que es en el fondo una tarea moral.

(9) Fichte, Ueber den Grund unseres Glaubens ( $F W \mathrm{~V}, 182=G A \mathrm{I} / 5,351)$. «Puede el Yo explicarse [erklären $=$ encontrar un fundamento de sí] a sí mismo [mediante fundamentos o razones que lo determinen, que determinen su esencia y su existencia]? ¿puede siquiera querer explicarse a sí mismo sin salir de sí y cesar de ser Yo? Donde cabe la posibilidad de pedir una explicación, allí con toda seguridad no se halla el Yo puro (absolutamente libre y autónomo); pues toda explicación hace dependiente. [...] Toda prueba presupone algo que no puede probarse en absoluto [=Aristóteles, Metafísica, libro IV]. Aquello de lo que parte la Doctrina de la ciencia no puede ser comprendido (begreifen) ni comunicado por medio de conceptos [la comunicación conceptual lo presupone; si alguien no es capaz de pensar por sí, tampoco será capaz de comprender lo que le decimos], sino que sólo cabe intuirlo inmediatamente (unmittelbar). [...] si hay alguna verdad, y en particular alguna verdad mediata (mittelbare) (mediante deducciones), ha de haber algo inmediatamente verdaderom (o.c., $F W \mathrm{~V}, 180-1$ nota $=G A \mathrm{I} / 5,350)$. Véase también Fichte, Zweite Einleitung § $10(F W \mathrm{I}, 508=G A \mathrm{I} / 4,260)$.

(10) Esa elaboración puede ser realiter e idealiter cuando se trata de su propia realidad libre, o sólo idealiter cuando se trata de la otra realidad o mundo. Entre medias, entre lo puro práctico y lo puro teórico, está toda la vida activa de la subjetividad en cuanto transformación del mundo. En realidad, los dos primeros son elementos que hemos de admitir para comprender la síntesis dinámica de esa vida activa y darle un sentido.

(11) «Pero sólo podemos comprender y comunicar a otros lo que podemos hacer nosotros mismos" (carta a Beck del 1 de julio de 1794; Ak. XI, 515). Véase también carta a J. Plücker de 26 de enero de 1796; Ak XII, 52, y Refl. 2394 y 2398 (Ak. XVI, 344 y 345); KU § 68 (Ak V, 384). 
Al contrario, por ejemplo, de lo que ocurre en Spinoza, para quien el pensamiento es sólo uno de los infinitos atributos de la substancia o realidad primera, aquí, en el idealismo, el saber de sí está en el corazón del primer principio o ser originario. Según Kant, a la libertad le es esencial su conciencia racional o imperativo categórico, en Fichte el Yo puro es a la vez ideal y real, en Hegel lo real es al mismo tiempo ser y concepto, substancia y sujeto, y esto último no como un mero atributo, sino como siendo la misma substancia. Eso es lo que hemos de comprender al final de la Lógica, y de la Filosofía real, en el Saber absoluto.

En Kant la estructura del "para sí̀ se expresa en la "a» de la "Apercepción» transcendental, que ha de acompañar toda representación, conocimiento, conciencia, etc. para que sean mías (autorreferencia); o sea, para que exista conciencia sin más (überhaupt) es preciso que ésta sea a su vez autoconciencia(12). Pero también la encontramos en la imputabilidad (Zurechnungsfähigkeit) moral y legal de las acciones(13), o en el criterio subjetivo del gusto estético y del genio creador. Este momento esencial del idealismo se acentúa en Fichte(14), que busca siempre explicar todo factum de la conciencia mediante las acciones de la subjetividad que lo convierte en algo elaborado por ella, al menos idealiter, y por tanto en algo real para ella; esto funciona como un principio metodológico básico de su filosofía(15).

(12) Ése es uno de los puntos básicos en la deducción transcendental de las categorías de la $K r V$; véase por ejemplo, su $\S 16$.

(13) «Persona es el sujeto cuyas acciones son imputables» (Kant, Metafísica de las costumbres Introducción IV, Ak VI, 223). "Nada es moralmente malo (es decir, capaz de ser imputado) sino lo que es nuestro propio acto" (Kant La religión dentro de los limites de la mera razón, I, 2, Ak VI, 31; véase también I, 1 y 3 (Ak VI, 21, 26 nota, 32, 35, 37, etc.).

(14) En la WL12 (Doctrina de la ciencia de 1812), Fichte llega a afirmar que ella no es sino "análisis del simple Sich» (GA II/13, 84).

(15) «Es preciso también señalar de paso que en una Doctrina de la ciencia son establecidos ciertamente facta y por eso se distingue, como sistema de un pensamiento real, de toda filosofía de fórmulas vacía (leeren Formular-Philosophie), pero en la Doctrina de la Ciencia no está permitido postular sin más algo como factum, sino que tiene que aducirse la demostración de que algo es un factum [...] Para expresarlo con más claridad: el Yo ha de explicarse todo factum; pero no puede explicárselo de otro modo que según las leyes de su ser, que son las mismas leyes según las cuales ha sido establecida la reflexión que hemos hecho hasta aquí. 
Éste es, sin duda, el punto que más se le discute al idealismo en la filosofía actual, exceptuando la fenomenología idealista de Husserl. En gran parte de la filosofía del s. XX se procede a una destrucción o deconstrucción del sujeto, al que se coloca como algo derivado, ya por influencia spinozista o nietzscheana, marxista o freudiana, heideggeriana o estructuralista, científico-lingüística o postmoderna. Lo conciben así señalando que lo que los individuos piensan y hacen está determinado por elementos o estructuras supraindividuales distintas de su conciencia reflexiva. Ante estas observaciones críticas podríamos señalar, primero, que no se ve que el acto mismo de pensar en cuanto tal no le puede ser dado al sujeto desde fuera, ni tampoco su libertad como acción originaria. Segundo, que el contenido que le pueda venir de fuera lo recibe porque lo hace suyo y sólo desde el momento en el que lo elabora desde sí y lo acepta para sí, pues en caso contrario no se enteraría de ello, no sería nada para él. En tercer lugar, la subjetividad no es sólo el individuo, sino que la subjetividad transcendental es tan individuo como comunidad, los dos a la vez, y de ella han de ser deducidos ambos(16); es esa subjetividad la que construye el lenguaje, lo comprende y la que es acotada por el mismo, la que crea la comunidad y la que puede en ella someter al individuo, la soberana y a la vez la súbdita de las mismas reglas y comprensiones. Si se afirma que las normas morales y las categorías del pensar proceden de otras instancias y no de la subjetividad, es porque se toma a ésta como lo meramente individual, no dándose cuenta de su carácter intersubjetivo, y tampoco se ve que, en todo caso, la subjetividad individual ha de elaborarlas desde sí, tanto las normas que le vienen de fuera como las categorías, si es que han de tener un significado y han de ser algo para ella. En cuarto lugar, la subjetividad

Esa manera que el Yo tiene de elaborar, de modificar y de determinar este factum, todo su modo de operar con el mismo, es a partir de ahora el objeto de nuestra reflexión filosófican (Fichte, Grundlage, FW I, 220-1 = GA I/2, 363-4).

(16) «Mi Yo absoluto no es, evidentemente, el individuum, le dice Fichte a Jacobi en carta del 30-8-1795 [...]. el individuo ha de ser deducido del Yo absoluto» (Carta de Fichte a Jacobi del 30 de agosto de 1795, GA III/2, 392). 
no se agota en lo que es o tiene de conciencia reflexiva, lo cual es como la punta del iceberg. La misma filosofía idealista alemana clásica se pone justamente como tarea el descubrimiento de los momentos prerreflexivos que hacen posible esa conciencia y que habían sido olvidados y cosificados. No parte propiamente de la conciencia (como hace el empirista) si se da a este término el sentido de una subjetividad cerrada que echa fuera de sí lo objetivo y real, sino que explica esa misma conciencia como momento de la experiencia, y la explica desde las acciones transcendentales subjetivas y las condiciones materiales transcendentalmente exigidas que la hacen posible, en las que la conciencia común no había reparado, sino que las había alienado, por lo que se hace necesaria su recuperación ontológica(17).

Esta atención al "para sí» es lo que distingue la filosofía idealista de la ciencia y de otras filosofías. La ciencia ha de explicar lo objetivo por lo objetivo. La filosofía idealista (en el sentido en el que se toma aquí este término) busca aclarar metodológicamente todo lo real y lo objetivo desde la acción con la que el sujeto lo elabora desde sí y lo convierte en experiencia para sí. La filosofía ha de comprender cómo lo real, también la propia realidad del Yo o del Espíritu (Hegel), se hace experiencia, se convierte en contenido para él, y cómo, por tanto, el sujeto puede hablar de ella con fundamento (en contra del escepticismo, pero también del dogmatismo que quiera ir más allá) y conferirle un sentido. Eso sólo lo puede explicar desde esa subjetividad fundante, porque sólo ella es saber, y por tanto toda acción ideal, de conocimiento, procede de ella, así como todo el sentido procede para el Idealismo de la libertad o del espíritu. El idealismo es una filosofía de la libertad, entendida claro está como una libertad racional, intersubjetiva. Ya Kant había declarado que la libertad

(17) Un análisis más detallado de éstos y de otros tópicos, presentes en gran parte de la filosofía actual, lo he llevado a cabo en el artículo "El primer principio en Fichte», editado en el libro El inicio del Idealismo alemán, Oswaldo Market y Jacinto Rivera de Rosales (Coordinadores), Editorial Complutense en coedición con la UNED, Madrid, 1996, pp. 63-102. 
es la piedra angular del sistema entero de la filosofía, tanto de su parte práctica como de la teórica(18).

\section{La finitud del ser originario}

Si el carácter de "para sí" de la subjetividad distinguía las filosofías idealistas de las materialistas (en sentido amplio, las filosofías que explican la subjetividad como producto de otras instancias), la finitud es aquí una marca que discrimina entre el método transcendental de Kant y de Fichte, y el método especulativo de Schelling y de Hegel. Más aún, cuando hablo del desarrollo fichteano del método transcendental, propiamente he de ceñirme al Fichte de Jena, cuya producción va de 1794 a 1800. Aunque esto es una cuestión discutida entre los especialistas de Fichte, considero que el segundo Fichte, el llamado Fichte de Berlín, se sitúa en otro ámbito del pensar que ya no es propiamente transcendental, aunque él afirme lo contrario, siga utilizando ese término, y se encuentren allí de hecho muchos instrumentos filosófico-metodológicos elaborados en la etapa anterior. El criterio que me lleva a esta afirmación es que el método transcendental, o sea, Kant y el Fichte de Jena, parte de una subjetividad originaria, sí, pero a la postre finita, mientras que el de Berlín lo hace desde lo Absoluto. En realidad plantea su sistema desde dos absolutos: desde el Absoluto como Ser, en donde desemboca su nueva preferencia por el realismo, eine Vorliebe für den Realismus, ${ }^{(19)}$ y el Absoluto como saber o fenómeno, que vuelve a ser el reino del idealismo, pero un idealismo del ben kai pan.

(18) Kant, $K p V$ A 4. Véase «Sobre el primado de la razón pura práctica en su unión con la especulativa" ( $K p V$, Ak. V, 119ss.), donde se nos dice: "porque todo interés es, en último término, práctico, y el interés mismo de la razón especulativa es condicionado y sólo en el uso práctico está completo» (121). Véase también KrV A 840, B 868; A 852-3, B 880-1; Grundlegung, Ak IV, 460 nota; y Fortschritte, Ak. XX, 345.

(19) Fichte, WLO4², GA II/8, 264. Véase también pp. 172 y 322. 
Sin embargo Fichte quiere evitar el dualismo, y lo hace declarando al primer absoluto como el único ser, mientras que el saber absoluto o concepto (del que todos formamos parte) es un mero Bild, mera imagen del primero o esquema, una imagen que a la postre ha de reconocer su nada, su vaciedad de ser, sich vernichten ${ }^{(20)}$, a fin de que se manifieste el Ser por vía negativa, a contrario ${ }^{(21)}$. Es una propuesta ontológica que puede rivalizar con la de Schelling o la de Hegel en su mismo horizonte, el que comparte con el neoplatonismo o con Spinoza, y en la que también estará Schopenhauer, y a través de él en gran parte Nietzsche ${ }^{(22)}$.

El método transcendental, por el contrario, tiene en cuenta la finitud de la subjetividad, de modo que el punto de vista transcendental no es el del hen kai pan, el de un monismo originario. Si se pretendiera lo contrario, si se quisiera filosofar desde el punto de vista de lo absoluto, se desembocaría irremisiblemente en contraposiciones dialécticas que son falsas o irresolubles, nos dice Kant, o que tienen que ser traducidas en clave moral, y comprendidas como exigencias de la libertad. La libertad es entonces el único ser absoluto del que se parte, pero no en el sentido de serlo ya todo desde el principio, sino en el sentido del "para sí», de estar absuelto de toda heteronomía, de partir desde sí. Si pretendemos otro absoluto, tanto teórica como prácticamente, la subjetividad entra en contradicción (dialéctica) consigo misma. Yo me atrevería a decir que eso es lo que ocurre incluso con los postulados de la inmortalidad (carencia de límite temporal) y de Dios (teísmo, omnipotencia), postulados en los que

(20) Fichte, WLO4², FW X, 139, 148, 152 = GA II/8, 96, 116, 122. "Todos los errores sin excepción consisten en que se toman imágenes por un ser» (Fichte, WL12, FW X, $365=$ GA II/13, 83).

(21) "Hen kai pan. Todo en el Uno, todo Uno [como quiere Spinoza con su substancia]. En efecto, a saber, en el único Fenómeno [no en la substancia o en el ser mismo de Dios]. En él vivimos, nos movemos, somos [se dice, refiriéndose a Dios o a la substancia]: ciertamente, en su Fenómeno: nunca en su ser absoluto» (Fichte, WL12, GA II/13, 60).

(22) «Este mundo que se crea eternamente él mismo, que se destruye eternamente él mismo, este mundo misterioso de la doble voluptuosidad, este mi más allá del bien y del mal, sin meta, [...] ciclo, [...] anillo que vuelve sobre sí mismo [...] es voluntad de poder y nada más» (Nietzsche, KSA 11, p. 611). 
se recogen visiones cristianas para responder a exigencias racionales que no han sido suficientemente elaboradas desde la forma transcendental de pensar. Por eso la inmortalidad entra en contradicción con las condiciones empíricas de la subjetividad, y Dios pone en serio peligro la libertad(23).

Veamos esta finitud en tres momentos esenciales de la misma.

1. Dualismo en la unidad. Decía que el método transcendental no parte de un monismo del hen kai pan. La subjetividad es ciertamente el modo esencial del ser originario, la fuente del sentido en el pensar y en la acción, pero tanto el yo ideal pensante, como el yo real actuante y libre, encuentran en frente a lo otro de sí que se le resiste, y al que han de objetivar y transformar. Kant lo expresa diciendo que carecemos de intuición intelectual, de capacidad creadora ex nibilo del mundo. Eso es lo que significa el "en sí» de la "cosa en sí», independientemente de que, al conceptuarla, utilice Kant el paradigma precrítico de la «afección» o bien lo elaboremos de forma más acorde con el método transcendental. Ese en sí o resistencia también originaria del mundo es lo que hace que nuestro conocer tenga un momento de pasividad, y que la transformación del mundo nos lance hacia un proceso ilimitado, un proceso histórico en cuanto a la legalidad, y un proceso personal en lo relativo a la moralidad (religión e inmortalidad): "la perfección es la meta suprema e inalcanzable del hombre, escribe Fichte; pero el perfeccionamiento ilimitado es su destino", un irse aproximando interminablemente a esa meta(24).

(23) «Para nuestra razón es enteramente incomprensible cómo deben ser creados seres en vistas al uso libre de sus fuerzas, porque según el principio de causalidad no podemos atribuir a un ser que aceptamos como producido ningún otro fundamento interno de sus acciones que el que ha puesto en él la causa productora, por medio de la cual (luego por medio de una causa externa) estaría entonces determinada cada acción del mismo, y por consiguiente ese ser no sería él mismo libre» (Kant, Religion, Ak VI, 142; véase también 121). Kant intenta una solución en la KpV A 179-184 recurriendo a la diferencia entre fenómeno y noúmeno, que a él mismo no le parece clara (Ak V, 100-103; véase también Metafísica de las costumbres $\S 28$ nota, VI, 280-281).

(24) Fichte, Ueber die Bestimmung des Gelehrten, final de la Lección primera (FW IV, 299$300=G A \mathrm{I} / 3,32)$, traducción en Istmo, Madrid, 2002, p. 59. Véase también Grundlage ( $F W$ I, $270=G A \mathrm{I} / 2,403-404)$. 
El método transcendental parte por tanto de un dualismo de origen, que no intenta diluir, y en eso consiste su respeto a la finitud, si bien en él se tiende a una unidad de sentido como tarea ilimitada, pues el sujeto ha de esforzarse por configurar toda realidad según las exigencias racionales de conocimiento y libertad. Ésa es la tensión básica que mueve al sujeto a conocer y a actuar, en virtud de la cual le surge un mundo, un sentido, una meta, un camino, y así ha de explicarlo la filosofía. Se trata de una tensión dinámica entre la identidad y la contraposición, o incluso la contradicción, o sea, entre la identificación y unidad del "para sín y la dualidad y facticidad del "en sí̀, contradicción que es el corazón y el motor de la subjetividad fichteana (me refiero al Fichte de Jena). El sujeto quiere la unidad y se encuentra con la dualidad, y tiene que realizar su identidad por medio de procesos interminables. Desde esos procesos se explica el surgimiento de la realidad para él.

Según Fichte, el Yo se enfrenta a un No-Yo, básicamente en el ámbito primario de la acción, y no propiamente en el ámbito secundario de la representación como pensaba Kant. Ese No-Yo que le limita es también absoluto, es decir, originario, aunque sólo en cuanto a la forma o sea, por lo que se refiere a su existencia, al $d a \beta$, a que se da, pues el No-Yo ha de ser dependiente del Yo en cuanto a su contenido(25), a su was, pues hay un predominio ontológico del Yo sobre el No-Yo, de la libertad sobre la cosa(26), y gracias a lo cual Fichte mantiene la unidad del sistema ${ }^{(27)}$. Por esa limitación originaria, el Yo puro se convierte en querer originario, como ya lo había pensado Kant con su razón práctica ${ }^{(28)}$. Es un querer que por su

(25) Ése es el segundo principio de la Grundlage (\$ 2).

(26) Kant había distinguido entre la dignidad de la persona y el precio de la cosa (Grundlegung, Ak IV, 426, 434-5).

(27) Es curioso el significado que Fichte da aquí al par materia-forma, pero no debe llevarnos a confusión, sobre todo sabiendo que son conceptos de reflexión (Kant, $\mathrm{KrV}$ A 266-268, B 322-324) y que por tanto significan cosas distintas según el asunto que estemos analizando con ellos.

(28) Obsérvese que esa primacía del querer se encuentra también en Schelling, Schopenhauer y Nietzsche. 
finitud aparece como Streben (esfuerzo, tensión), Tendenz (tendencia), Trieb (impulso) ${ }^{(29)}$, y toma conciencia de sí en cuanto Sebnen (anhelo) -anhelo de lo que se es, en sentido de Realität, y a la vez de lo que se carece, en el sentido de Wirklichkeit-, y a la postre como imperativo (moral). De este modo, la dualidad originaria se instala en el interior del mismo Yo y es también para el Yo, le desgarra, le pone en macha, en camino, en acción, interminablemente. Por eso, el Yo se abre al mundo, o mejor dicho está abierto desde siempre (constitutivamente) al mundo por ese sentimiento de anhelo, de carencia, por su finitud sentida, sabida, pero también porque su acción ideal es ilimitada en cuanto ideal, supera los límites y los objetiva, objetiva el mundo y hace posible su transformación desde intereses de la subjetividad. No es un Yo cerrado y cósico, sino una acción abierta, sintética y transformadora. No hay Yo sin mundo, o una intuición intelectual que no esté acompañada de intuición empírica: "La intuición intelectual también está ligada siempre con una empírica», afirma Fichte, implícitamente contra Schelling(30).

2. ${ }^{\circ}$ El factum de la forma. La filosofía transcendental, partiendo de esa subjetividad originaria pero finita, no ha de explicar el surgimiento material del mundo, como lo hace Schelling y Hegel, o incluso el segundo Fichte, sino que se limita a explicar cómo el mundo, la realidad y el mismo Yo es idealiter "para" el Yo. No es que el mundo sea amorfo para Kant y con las categorías yo lo configure realmente, como lo puede hacer el Demiurgo platónico, sino que con ellas el sujeto lo objetiva mediante una acción ideal, lógico-transcendental. Por tanto, ese idealismo ha de explicar la forma de dicha apropiación que llamamos «objetividad», de ese "para sí1, o sea, ha de señalar las acciones ideales que hacen esto posible. Pues bien, esas mismas

(29) No podemos decir que el Yo puro sea aquí independientemente de ese Trieb, o sea, que fuera pleno ya en algún lugar ontológico o modo de ser, mientras que eso sí es lo que ocurre con el Ser absoluto en el Fichte de Berlín.

(30) Zweite Einleitung, $F W$ I, $464=$ GA I/4, 217. Véase también WLnm, GA IV/3, GA IV/3, 435. Sittenlebre ( $F W \mathrm{IV}, 91$ y $102=G A \mathrm{I} / 594$ y 102). 
formas a priori con las que primariamente interpretamos el mundo, son para la subjetividad y la filosofía un factum, dice Kant. Hablando en absoluto podrían haber sido otras, como podrían haber otras subjetividades que no operaran con el espacio y el tiempo (31), sólo que con ellas no podríamos formar comunidad, no compartiríamos saber ni ciencia, pues no sería posible encontrarnos en un mundo de objetos.

Fichte trata de disolver este factum deduciendo las formas a partir de las acciones del Yo (va de arriba a abajo), mientras que Kant para deducir las categorías toma de la lógica la tabla de los juicios (va de abajo a arriba). Pero en realidad lo único que Fichte logra es mostrar que las formas transcendentales son coherentemente las de nuestro mundo, mas no que fueran imposibles mundos distintos en virtud de otros tipos de subjetividad, es decir, mediante otras formas que fueran entre sí igualmente coherentes. Hay ahí una cierta facticidad irrebasable, si bien sólo como concepto meramente negativo que no nos habilita para hablar de otros seres y hacer metafísica-ficción.

3. ${ }^{\circ}$ Más aún, dicha finitud impregna de facticidad a la realidad en su conjunto. Mientras que la substancia de Spinoza incluye en sí su propia existencia, de manera que existe con absoluta necesidad (no puede no existir) ${ }^{(32)}$, y lo mismo le ocurre a la Idea en Hegel, para Kant, por el contrario, la existencia no está en el orden de los conceptos, de modo que en absoluto podría no existir nada, pues no sería contradictorio pensar esa posibilidad. Sí sería transcendentalmente contradictorio decir que no existe el mundo, pues al decirlo existo, y la realidad del mundo es una condición transcendental necesaria para la existencia de la subjetividad, como se prueba en la "Refutación del idealismo»(33).

(31) Kant, $K r V$ B 145-146, pero también A 19, B 33; A 26-7, B 42-3; A 35, B 51; A 37, B 54; A 42, B 59; B 72, 150, etc.; Entdeckung, Ak VIII, 249.

(32) Spinoza, Ética I, Proposiciones VII, XI y XX.

(33) Kant, $K r V$ B 273-279. 
Es decir, el método transcendental es en el fondo hipotético, o dicho de otra manera, sólo alcanza una necesidad hipotética: si se da la conciencia, si se da la subjetividad, entonces es necesario que exista el mundo y que responda a estas idealidades transcendentales, pues en caso contrario no tendría lugar dicha conciencia. Pero hablando en absoluto sería posible que no existiera nada. Ante la pregunta leibniziana de por qué hay algo en lugar de nada, y que Leibniz contesta apelando a un Ser necesario a través de su principio de razón suficiente(34), tendríamos que responder aquí por el contrario con la gratuidad del ser(35). Lo mismo sucede en Fichte, aunque él no reflexione expresamente sobre este asunto; su Yo está, en efecto, a expensas de que se dé el No-Yo, pues eso no depende de él, y sin embargo lo exige, dado que sin el No-Yo él tampoco llegaría a la existencia(36). No hay fundamento para ese daß o dación del No-Yo más allá de una exigencia transcendental que no logra crearlo, y por tanto es asimismo un don, aunque sea el don del límite. En consecuencia, éste es tan originario como el Yo (37). Esta idea continúa estando presente incluso en el sistema del Fichte de Berlín, no ciertamente en relación con el Ser absoluto, que en su mismo concepto se anuncia "como no pudiendo no

(34) Leibniz, Principios de la naturaleza y de la Gracia fundados en razón, §§ 7ss. Es una cuestión que retoma Schelling en su Filosofía de la revelación: "¿por qué existe algo? ¿por qué no existe nada?» (Cotta, XIII, 7), y de nuevo también se remite a la historia o génesis divina.

(35) Este asunto lo he tratado en el artículo «La aportación ontológica de Kant. Un diálogo abierto con Heidegger", publicado en Aktuelnost y buduchnost Kantove filozofie. Ysjod jedne mejdunarodne filozofske ankete povodom dvestogodinischnie Kantove smsrti (1804-2004) [Actualidad y futuro de la filosofía de Kant. Cuestionario internacional con ocasión del 200 aniversario de la muerte de Kant], dirigido por Danilo Basta, Editorial Guteniergov Alaksia, Belgrado, 2004, pp. 239-263.

(36) «El Yo nunca se hará ni podrá hacerse consciente de sí mismo ly por tanto no podrá ser Yo, luego no podrá ser] sino en sus determinaciones empíricas y esas determinaciones empíricas presuponen necesariamente algo fuera del Yo" (Fichte, Vorlesungen über die Bestimmung des Gelebrten, FW VI, 294-295 = GA I/3, p. 28).

(37) "También la limitación es originaria, tan originaria como la voluntad pura misma" (Fichte, WL nova methodo, Meiner, p. 163). "Yo estoy originariamente limitado, también hay en mí originariamente una multiplicidad de sentimientos, eso no lo puede cambiar, es la condición de todo mi ser, no puedo ir más allám (o. c., 74). La cuestión del límite en el Fichte de Jena no se reduce naturalmente a esa dación del No-Yo, sino que conlleva otras acciones, de lo cual me he ocupado en el artículo "Die Begrenzung. Vom Anstoß zur Aufforderung", publicado en Fichte-Studien n. ${ }^{\circ} 16$ (1999), pp. 167-190. 
ser» (38), sino por lo que se refiere al saber absoluto. Éste acoge su propia existencia primariamente como una "facticidad": su concepto no implica necesidad, pues no podemos introducirnos en el Ser absoluto y ver ahí su fundamento. Aunque una vez dado, puede afirmarse su necesidad, ya que en Dios no hay movimiento o cambio (39).

El punto más categórico según el método transcendental, la fuente máxima de toda necesidad para él, es la libertad y su ley moral, su tarea de realizarse. Pero la existencia de ésta y el mundo donde ha de realizarse son algo que ella misma no puede procurarse enteramente desde sí. Ésa es su radical finitud. Este punto de la finitud emparienta el método transcendental con la fenomenología, y también con Heidegger y la hermenéutica. Casi toda la filosofía actual quiere adoptar ese principio, aunque a veces de hecho no lo consiga.

\section{El modo genético de deducción}

El modo genético de deducción es el elemento metodológico con el que Fichte contribuye más decisivamente al desarrollo y reformulación del método transcendental respecto a su versión kantiana. Es por cierto un aspecto que compartirá con los otros dos grandes idealistas, Schelling y Hegel, los cuales lo aprenden en gran parte de él, al menos inicialmente, aunque después lo desarrollan con características marcadamente personales. Es a la vez un modo de filosofar que lo distancia de la fenomenología y lo acerca al neoplatonismo, en parte a Spinoza y (aun sin saberlo) a todas las

(38) Fichte, WL12, GA II/13, 53 (líneas 25-26). "Así [pensaba] Spinoza, así [pensamos] nosotros» (o.c., 51, 1. 21).

(39) Véase, por ejemplo, Fichte $W L 04^{2}$, GA II/8, 43-49, 91-93, 339; WLO5, GA II/9, 187, 189 NB, 211; WL11, GA II/12, 165, 170-172; WL12, GA II/13, 58. 
genealogías de la moral o del poder que se hacen hoy (Nietzsche, Foucault) si bien desde parámetros diferentes.

Mientras que Kant era más bien un "geógrafo" de la subjetividad, Fichte nos quiere ofrecer "la historia pragmática del espíritu humano»(40). Kant parte de una idea que ordena arquitectónicamente los elementos que configuran nuestras diversas experiencias: la objetiva, la moral y la estética. Por ejemplo, para encontrar la tabla de las categorías utiliza la idea de comprender los conceptos como funciones (predicados) de juicios, y a las categorías o conceptos primarios como aquellas reglas que hacen posible las distintas clases de juicios ${ }^{(41)}$. Gracias a esa idea arquitectónica, Kant se eleva desde la experiencia próxima a la conciencia reflexiva, como es la tabla de los juicios y la lógica formal, a sus condiciones transcendentales de posibilidad, que son las categorías ${ }^{(42)}$ y en última instancia la Apercepción transcendental, o incluso va más allá y afirma que la libertad es la piedra angular de todo el sistema, tanto del teórico como del práctico.

Fichte, aprovechando todo ese viaje de descubrimientos iniciado por Kant, elabora sobre todo el camino de retorno, el que va del Yo a la experiencia, mostrando cómo se genera ésta desde acciones y necesidades subjetivas transcendentales. O mejor dicho, hace un doble recorrido. En primer lugar procede a un corto movimiento de ascenso desde la conciencia común hasta el primer principio filosófico. En el $\S 1$ de la Grundlage (1794-5) asciende desde la conciencia indubitable del principio de identidad (A es A) hasta la acción de identificación del Yo consigo mismo: Yo soy Yo = Yo soy; en la Sittenlebre de 1798, parte de la experiencia primaria de la conciencia

(40) Fichte, Grundlage (FW I, $222=$ GA I/2, 365). Véase también Ueber den Begriff der WL $(F W \mathrm{I}, 77=G A \mathrm{I} / 2,147)$.

(41) $K r V$ A 67-69, B 92-94.

(42) La tabla de los juicios sirve de ratio cognoscendi de las categorías, porque éstas son la ratio essendi de las distintas clases de juicios o modos de decir el "es» objetivo de los mismos. 
práctica: «yo me encuentro queriendo algo» (§ 1), y se encamina al imperativo categórico $(\$ 3)^{(43)}$.

En un segundo momento, Fichte deduce toda la realidad del mundo desde la actividad del Yo. No ciertamente toda la realidad de manera realiter, al igual que lo hace el idealismo especulativo de Schelling y Hegel, así como el Fichte de Berlín, según los cuales el mundo surge también materialiter de un Yo cosmogónico, o de la Idea absoluta, o del Saber absoluto, entendidos como hen kai pan, sino sólo idealiter, es decir, en cuanto siendo para el $Y_{O}^{(44)}$ (no podríamos hablar de otra realidad, de una que fuera transcendente y por tanto radicalmente desconocida); es por tanto una deducción que no puede anular la finitud del Yo. Este modo de explicación es el propio de la filosofía idealista en su versión transcendental, el que hace aparecer todo lo real para el Yo desde las acciones ideales con las que éste comprende los diferentes entes y modos de ser.

Esbocemos los tres principios metodológicos fundamentales con los que se delinea esta génesis.

1. ${ }^{\circ}$ En primer lugar tenemos la identidad, requerida por el "para sí». Es lo que busca el Yo, al igual que la Idea hegeliana, en todos los meandros y contraposiciones del proceso que describe el sistema. El filósofo ha de mostrar cómo el Yo intenta restablecerla y hasta qué punto lo logra en cada uno de esos momentos. Este restablecimiento surge siempre de la autonomía del Yo, de su inagotable poder creativo y autogenerativo, pues su ser es autoposición, Setzung, Tathandlung, acción espontánea. Es la

(43) Este ascenso estaría amplísimamente replicado en la Fenomenología del Espíritu de Hegel, entendida como preludio al sistema, como subida hasta el saber absoluto.

(44) «En mi Doctrina de la Ciencia atribuyo al ser finito una imaginación creadora, es decir, una facultad de crear absolutamente la materia; se entiende que la materia ideal, para la representación, pues para un ser finito no se puede hablar de otra» (Fichte, "Erklärung», GA I/3, 213). "El mundo, el mundo dado y real, la naturaleza, pues sólo hablo de ella, tiene dos lados: es producto de nuestra limitación; [y a la vez] es producto de nuestro libre actuar, se entiende que de nuestro actuar ideal (no de nuestra acción efectiva real)" (Fichte, Sittenlebre; $F W$ IV, $354=G A$ I/5, 308). Véase también Zweite Einleitung ( $F W$ I, 494 y 495 nota = GA I/4, 248 y 249 nota). 
misma capacidad creativa que se muestra por ejemplo en el ámbito del arte, o de la filosofía.

2. ${ }^{\circ}$ Ahora bien, el Yo está a la búsqueda de su identidad porque se encuentra de principio con la división, la escisión, la herida, el desplazamiento de sí, en suma, la oposición introducida realiter por lo otro de sí, por el No-Yo (fundamento real), y que él ha de elaborar desde sí a fin de que sea para él (fundamento ideal) ${ }^{(45)}$. De ese modo, la limitación real introduce lo otro en él y fractura su identidad. Pero eso no lo hace sin más desde fuera, sino que esa oposición está ya también en el Yo y por el Yo, como exigencia transcendental de la subjetividad. En efecto, el "para sí» como acto de identificación engloba la diferencia, y sólo ante ella llega a realizarse, pues el Yo no logra saber de sí, o sea, ser, si no se distingue de lo otro de sí. Esto se debe a que toda conciencia requiere contraposición, alteridad, distinción (46); ése es el fundamento ideal del No-Yo, por el cual éste es real para el Yo. En consecuencia, esa limitación ha de aparecer también como acción del Yo sobre sí mismo, como autolimitación, puesta en el Yo por él, pues sólo así es enteramente para él. De ese modo hemos de entender el espacio y el tiempo en cuanto formas a priori en relación con lo cósico, y el imperativo categórico en relación con la libertad y sus individualidades. El Yo, para conocerse y realizarse como Yo, se abre al mundo, o mejor dicho, está abierto al mundo, teórica y prácticamente. Por eso se encuentra con el No-Yo, no a la inversa, pues la iniciativa procede del Yo y sólo así es para el $\mathrm{Yo}^{(47)}$.

(45) Fichte, Grundlage, $F W$ I, $174=$ GA I/2, 325. Véase también $F W$ I, $187=G A$ I $/ 2,336$.

(46) En el mismo corazón de la identidad, nos dice Hegel en su Lógica de la esencia, está la distinción, la oposición, e incluso la contradicción, pues se trata de un acto de identidad consigo mismo, y ese "mismo", ese Selbst, requiere contraposición, negación, retorno (Hegel, Wissenschaft der Logik I, 2, 1, 2, Werke, Suhrkamp, Frankfurt, 1969, t. 6, pp. 38ss.). Es el trabajo negativo del concepto.

(47) «El NoYo no se topa con el Yo, sino el Yo con el NoYo en su expansión. [...] El NoYo no comienza, él es sólo el que obstaculiza, el que detiene. El Yo no puede llegar a la conciencia si no está limitado; el fundamento de la limitación se halla fuera de él, pero el fundamento de la actividad se halla en él» (Fichte, WL nova methodo, Meiner, p. 74). 
En el corazón del "para sí», en su propia intimidad, el Yo es necesariamente apertura, y no otra cosa son las estructuras transcendentales: no cerrazones ${ }^{(48)}$, sino transparencias. Es importante darse cuenta del carácter sintético de ese Yo, que no es un yo cerrado o cósico, sino una acción sintética, que por su finitud sólo logra síntesis dinámicas, en las que consiste la experiencia, la realidad del mundo y del Yo mismo. Esta ley de la necesaria contraposición ejerce en Fichte en realidad el papel del segundo principio, del cual van saliendo las diferentes limitaciones o momentos del sistema(49). Pero eso es así porque en dicha contraposición el Yo siempre se busca a sí mismo, siempre intenta restaurar su identidad, al igual que pasará con la Idea en Hegel, que en dinámico equilibrio se va buscando a través de todas las contraposiciones o contradicciones hasta que se alcanza en la última etapa al Espíritu absoluto.

3. ${ }^{\circ}$ Por último, esa identificación y esa diferencia no se llevan a cabo plenamente de manera inmediata (unmittelbar), en un solo movimiento, sino que se articulan a través de diversas etapas que integran el sistema. Aquí descubrimos que la limitación tiene múltiples caras o momentos (contados, finitos, pues en caso contrario no habría sistema), cada uno de los cuales engloba a su vez una multiplicidad ilimitada. Y vemos que el "para sí» se dice de dos maneras, tiene dos significados o modalidades.

En primer lugar, la distinción se hace desde varios respectos. Por ejemplo, el Yo se ha de distinguir del No-Yo, pero también de los otros yoes en cuanto individuo. Y en estas mismas distinciones él tiene a la vez que identificarse y distinguirse de múltiples maneras y mediaciones. El filósofo ha de ir descubriendo las diversas condiciones involucradas en las mismas, que dan lugar a diversos momentos del sistema. Por ejemplo, si ha de ser posible la

(48) En cuando cerrazones es como muchas veces se han interpretado las estructuras transcendentales, asimilando Kant a Hume, o a Fichte con Berkeley.

(49) "Todo el mecanismo del espíritu humano reposa sobre la necesidad de oponer (auf der Nothwendigkeit des Entgegensezens)» (Fichte, WL nova methodo, § 2, GA IV/3, 356). 
conciencia de la libertad es necesario contraponerse con el No-Yo, pero a la vez el Yo ha de atribuirse una causalidad propia sobre el No-Yo, y para eso es necesario que éste le ofrezca una resistencia con sus propias leyes y que el Yo se identifique con la causalidad física de un cuerpo, etc. (50) Surgen así diversas limitaciones o articulaciones de la limitación que hacen posible la subjetividad como pensar y actuar.

Esta multiplicidad surge asimismo, en segundo lugar, porque el Yo no capta toda la complejidad de lo real de una vez. Esto se basa en que primero actúa, y después cuando reflexiona sobre esa primera actuación sólo «encuentra» (no hace) el resultado de la misma, de modo que en esa primera reflexión no puede comprenderlo como producto de su propia acción; en consecuencia, lo considera ajeno a él, lo aliena, y tiene que realizar un periplo de reflexiones para recuperarse a sí mismo (51). De ahí la diferencia entre la visión que va teniendo el Yo durante ese proceso y lo que va viendo el filósofo (el "Nosotros» de la Fenomenología del Espíritu de Hegel). La filosofía se plantea como una anámnesis o camino reflexivo hacia la plena conciencia de sí, una elevación del Yo hasta el punto de vista del filósofo, momento en el cual se cierra el círculo y el sistema está completo. La filosofía ha de mostrar todas esas etapas, si bien en cada una se implementa una multiplicidad ilimitada que correspondería ya a un estudio empírico; por ejemplo, la filosofía ha de señalar la necesidad de que se dé una naturaleza orgánica como punto de unión de subjetividad y objetividad, pero no le corresponde ya el estudio empírico de las formas y variedades de animales y plantas, ni menos aún el de sus individuos.

Este ciclo o círculo sistemático nos lleva, por último, a distinguir dos tipos de "para sí». El primero y fundante es la autoconciencia transcendental que hace posible toda conciencia, todo Yo, en cualquier etapa que se

(50) Véase, por ejemplo, Fichte, Sittenlehre de 1798, §§ 4ss.

(51) «Lo que llamamos naturaleza es un poema cifrado en maravillosos caracteres ocultos. Pero si se pudiera desvelar el enigma, reconoceríamos en él la odisea del espíritu que, burlado prodigiosamente, huye de sí mismo mientras se busca» (Schelling, Sistema del idealismo transcendental, Cotta III, 628). 
encuentre, desde el sentimiento hasta la razón, desde el estado de coma hasta la claridad de la reflexión filosófica. Es una presencia a sí constituyente, una autoconciencia no objetivada ni objetivable sino fundamento de toda subjetividad y conciencia, lo que Kant denomina Apercepción transcendental, y Fichte Tathandlung e intuición intelectual. Es la transparencia primaria, inmediata, insobornable, como lo demostrara ya Descartes, fundamento de toda identificación y diferencia. El otro tipo de autoconciencia podríamos llamarla "reflexiva», o incluso empírica, la que tiene lugar en el retorno hacia sí para diferenciarse real o empíricamente de lo otro ${ }^{(52)}$. Es la autoconciencia que el Yo va adquiriendo de sí en el recorrido de los momentos y etapas, así como en su vida real y empírica, y la que se completa cuando llega al punto de vista del filósofo idealista y reconoce plenamente todo lo que es, todo lo que ha hecho. Este segundo "para sín, que por tanto tiene a su vez muchos niveles de complejidad y diferenciación, no sería posible sin el primero, pues no se daría una autoidentificación en el retorno si no hubiera ya un saber de sí desde el inicio que hiciera esa operación y que sabe de todo el recorrido unificándolo, que acompaña (begleiten), diría Kant ${ }^{(53)}$, todo el proceso, pero no externamente, sino constituyéndolo como tal, como experiencia de un sujeto, o sea, como experiencia. También en ese sentido, al final se cierra el círculo, pero sólo del saber filosófico, pues quedarán siempre abiertas la praxis y la póiesis, el saber científico, e incluso la formulación acertada del sistema mismo de filosofía.

Pues bien, cuando se ha hablado del "para sín" como transparencia del sujeto a sí, que es uno de los puntos más álgidos del ataque a estas filosofías por parte del pensamiento actual, me refería primariamente a la autoconciencia constituyente o transcendental. La otra, la transparencia de la autoconciencia reflexiva, no puede lograrse de manera inmediata,

(52) En la "Refutación del Idealismo", que Kant inserta en la segunda edición de su $K r V$, se nos muestra el sentido interno como conciencia empírica del yo configurándose en comparación con los fenómenos externos, en una especie de retorno del yo hacia sí (B 274ss.).

(53) $K r V$ B 132-136. 
y enteramente sólo en el nivel transcendental (filosófico), no empírico. Hemos visto cómo el Yo no comprende bien lo que va sucediendo en el 100 proceso, y la filosofía transcendental y el Idealismo alemán se plantean justamente recuperar esos orígenes olvidados, o sea, se proponen la superación de esa ceguera que el Yo tiene necesariamente (no casualmente) de sí hasta que se alza a la filosofía, en donde se logra llevar a la conciencia reflexiva todos los estadios prerreflexivos que la hacen posible. Por eso no se toma como suelo la conciencia común, sino que se ha de explicar sus ilusiones y engaños, aunque como momentos necesarios en el proceso del saber, del saber de sí. 



\section{Série}

\section{Documentos}

Imprensa da Universidade de Coimbra

Coimbra University Press

2007

- U

C • 